\title{
Changes in clinical and laboratory features of Kawasaki disease noted over time in Daejeon, Korea
}

\author{
Hong-Ryang Kil ${ }^{1}$, Jae-Won Yu' ${ }^{1}$, Sung-Churl Lee ${ }^{2}$, Jung-Woo Rhim ${ }^{2}$ and Kyung-Yil Lee ${ }^{2^{*}}$ (D)
}

\begin{abstract}
Background: Kawasaki disease (KD) becomes one of the common diseases in Korea. Changes in clinical features and laboratory findings of KD were evaluated over a period of 10 years.

Methods: We reviewed the medical records of KD patients and compared the clinical and laboratory features of two KD patient groups: those admitted from 2000 to 2004 (group A, 284 cases) and those admitted from 2010 to 2014 (group B, 331 cases).

Results: There were a total of 615 KD patients (mean age: 29.7 months; male-to-female ratio = 1.6:1), including 228 incomplete KD patients. Incomplete KD patients had milder values in some laboratory indices. The preadmission and total fever durations were longer in group A than in group B. The proportion of incomplete KD was higher in group B, but incidence of coronary artery lesions (CALs) was lower. For laboratory indices, the C-reactive protein and follow-up platelet values were lower, and the hemoglobin and albumin values were higher in group B. The same clinical and laboratory findings were confirmed in the KD subgroups; those with the same fever duration of 5 or 6 days and same ages, those with complete KD, and those with incomplete KD in the two different time periods. Conclusions: Our findings suggest that clinical features of KD tend to be milder over time and manifest in a higher incidence of incomplete KD, lower incidence of CALs, and less severe laboratory findings in recent KD patients in Korea compared with their historic counterparts.
\end{abstract}

Keywords: Kawasaki disease, Epidemiology, Clinical signs, coronary artery lesions

\section{Background}

Kawasaki disease (KD) is an acute self-limiting systemic inflammation that can involve multiple organs, especially the heart via coronary artery lesions (CALs) [1]. KD is a newly appeared disease in the East Asian countries, including Japan, South Korea, Taiwan and China; though infantile polyarteritis nodosa, which may be a severe form of KD, has been reported in the Western countries since the late nineteenth century [2]. KD began being reported in Asian countries in specific time periods: in the early 1960s in Japan, 1970s in Korea and in 1970-80s in Taiwan and China, and possibly 1990s in India and other economically grown Asian countries [3-7], which

\footnotetext{
* Correspondence: leekyungyil@catholic.ac.kr

2Departments of Pediatrics, Daejeon St. Mary's Hospital, College of Medicine, The Catholic University of Korea, 64 Daeheung-ro, Jung-gu, Daejeon 34943, Republic of Korea

Full list of author information is available at the end of the article
}

suggests that economic growth and westernization of these countries are associated with the emergence of KD $[8,9]$. KD has shown epidemiological characteristics in these countries; it has the same age predilection of 6 months -4 years and has become a nationwide endemic disease within 2 decades with the incidence slowly increasing after its first report. Additionally, KD occurs throughout the year with slight monthly and regional variations. On the other hand, the incidence of $K D$ in Western countries is lower by tenth to one twentieth to Asian countries and has plateaued during recent decades [10]. These unique epidemiological characteristics are not observed in any newly emerging infectious diseases, such as acquired immune deficiency syndrome (AIDS) and severe acute respiratory syndrome (SARS). Thus, it is proposed that $\mathrm{KD}$ may be an acute immune-mediated disease that develops after an infection with an unknown 
pathogen(s) in genetically susceptible immune-immature young children, and that the immunopathogenesis of KD may be similar to that of infection-related immunemediated diseases such as acute rheumatic fever rather than that of infectious disease such as scarlet fever [9].

It has been reported that epidemiological and/or clinical characteristics of infectious diseases, including scarlet fever, and infection-related immune-mediated diseases, including acute rheumatic fever and acute post-infectious glomerulonephritis (APSGN), have changed over time [11-13]. Nationwide epidemiological studies in Japan and Korea have reported that the epidemiology of KD has also changed over time, including increased incomplete $\mathrm{KD}$ and less severe CALs in recent patients compared to past KD patients [14, 15]. We also independently observed similar results in neighboring hospitals in Daejeon, Korea, which suggests that KD in recent patients has a milder phenotype compared to that in past KD patients $[16,17]$.

In this study, we evaluated clinical and laboratory findings of Korean KD patients to determine if there were changes in recent KD patients compared to past KD patients. We also discussed clinical implications of changing KD epidemiology in Korea.

\section{Methods}

This study was conducted in two university hospitals in Daejeon, Korea: Chungnam National University Hospital $(\mathrm{CNUH})$ and The Catholic University of Korea Daejeon St. Mary's Hospital (DSMH). To evaluate the changes in clinical features more clearly, we divided the subjects into 2 groups according to their time of admission, a decade-interval apart.

We reviewed medical records of a total of $615 \mathrm{KD}$ patients: those admitted between January 2000 and December 2004 (the 2000-2004 group, $n=284$ ) and those admitted between January 2010 and December 2014 (the 2010-2014 group, $n=331$ ). The selection of KD was based on clinical diagnostic criteria guidelines established by the Japanese Kawasaki Disease Research Committee or the American Heart Association (AHA) $[1,18]$. There were 330 cases from $\mathrm{CNUH}$ and 285 cases from DSMH. KD patients that had spontaneous defervescence without IVIG treatment during hospitalization were excluded ( 28 cases).

Complete KD is defined as having fever of $\geq 5$ days with at least 4 of the 5 principal clinical signs: 1) bilateral conjunctival injections, 2) changes in the lips and oral cavity, 3) polymorphous exanthema, 4) changes in the peripheral extremities, and 5) acute nonpurulent cervical lymphadenopathy. Incomplete KD was defined as having fever of $\geq 5$ days with 3 or fewer principal signs, with or without cardiac lesions once other KD-like diseases with similar findings had been excluded. Because the diagnosis of KD in this study was made by experts in KD, independently, at each hospital during the study period (HR Kil and KY Lee), there were few differences in the policy of diagnosis and IVIG treatment in this study.

Laboratory parameters were examined at least twice during hospitalization at presentation and at discharge. All patients underwent 2D-echocardiography of the coronary arteries during hospitalization and again at approximately 1 or 2 months after discharge. Echocardiographic findings that were performed during hospitalization were analyzed. CALs were defined as ectasia when there was coronary arterial dilatation $\leq 4 \mathrm{~mm}$ in children that were younger than 5 years or $\leq 5 \mathrm{~mm}$ in children that were 5 years or older, or when the diameter was $<1.5$ times the size of the adjacent coronary artery. Aneurysm was defined as coronary artery dilatation in excess of that ascribed to ectasia, according to the Japanese Ministry of Health and Welfare guidelines [18]. We compared the clinical and laboratory indices between the groups.

\section{Statistical analysis}

All calculations were performed using SPSS ver. 14.0 (SPSS Inc., Chicago, IL, USA). Continuous variables were expressed as mean \pm standard deviation. Student's t-test for continuous variables was used for comparisons between the groups. The Pearson's Chi-square test was used for categorical variables. A $P$ value less than 0.05 was considered statistically significant.

\section{Results}

\section{Clinical characteristics of total KD patients}

The mean age of all of the KD patients $(n=615)$ was 29.7 \pm 21.3 months, and the male-to-female ratio was 1.6:1 (385:240). Among the total patients, 387 showed complete $\mathrm{KD}$ and 228 showed incomplete KD at presentation. The prevalence rates of clinical diagnostic signs of the eyes, lips, skin rashes, extremity changes, and cervical lymphadenopathy were $92.7 \%, 84.1 \%, 63.4 \%, 81 \%$, and $51.7 \%$, respectively. In complete KD patients $(n=387)$, the prevalence rates were $96.9 \%, 96.1 \%, 86.3 \%, 93.8 \%$, and $63.0 \%$, respectively, and $35.9 \%$ of the patients $(139 / 387)$ had all 5 diagnostic signs. In incomplete KD patients $(n=228), 149$ patients had 3 diagnostic signs, and 79 patients had $\leq 2$ diagnostic signs ( 5 patients had one sign of lymphadenopathy). IVIG treatment for incomplete KD was based on laboratory indices; incomplete KD patients in the 2000-2004 group, before the 2004 AHA guidelines were published, had WBC count of $>10,000 / \mathrm{mm}^{3}$, neutrophil differential of $>50 \%$, and CRP level of $>2 \mathrm{mg} / \mathrm{dL}$ in the early stage of the illness with repeated examinations, and they showed an increased platelet count at follow-up examination after IVIG treatment [16, 19]. Diagnosis and IVIG treatment of incomplete KD patients in the 2010 2014 group were referred to the AHA guidelines [1]. All 
patients received IVIG $(2 \mathrm{~g} / \mathrm{kg})$ for $10-12 \mathrm{~h}$, and the mean duration from admission day to IVIG infusion day was $1.2 \pm 0.9$ days. A majority of KD patients $(89.1 \%, 548 / 615)$ received IVIG within $48 \mathrm{~h}$ after admission, and there was no difference in time-gap between the 2000-2004 group and the 2010-2014 group (1.2 \pm 1.0 days vs. $1.2 \pm 0.9$ days, $P=0.732)$. However, the incomplete KD group received IVIG later than the complete KD group $(1.4 \pm 2.1$ days vs. $1.1 \pm 0.9$ days, $P<0.001)$.

\section{Comparison of clinical features between complete KD and incomplete KD}

Epidemiological and clinical data of complete and incomplete KD groups are shown in Table 1 . There were no significant differences in clinical parameters between the two groups based on age, sex, duration of fever, or proportion of CALs. The mean hospitalization time was longer (7.6 days vs. 6.6 days, $P<0.001$ ) and the proportion of repeated IVIG-treated cases was higher in the complete KD cases $(11.9 \%$ vs. $5.7 \%, P=0.015)$. Laboratory parameter analysis indicated differences in some parameters, including neutrophil/lymphocyte differential, CRP $(10 \mathrm{mg} / \mathrm{dL}$ vs. $8.8 \mathrm{mg} / \mathrm{dL}, P=0.016)$, albumin $(3.6 \mathrm{~g} / \mathrm{dL}$ vs. $3.7 \mathrm{~g} / \mathrm{dL}$, $P=0.004)$, and ALT (127 IU/L vs. $95 \mathrm{IU} / \mathrm{L}, P=0.018$ ), between the groups. In ALT, $42.4 \%$ of complete KD and $53.9 \%$ of incomplete KD were not increased at presentation $(P=0.006)$, and $36.7 \%$ of complete KD and $24.1 \%$ of incomplete KD had values $>100 \mathrm{IU} / \mathrm{L}(P=0.001$, Table 1$)$.

\section{Comparison of epidemiological and clinical features} between the 2000-2004 group and the 2010-2014 group Demographic, clinical, and laboratory parameters are shown in Table 2. The mean age and male-to-female ratio did not differ between the groups. In terms of clinical features, fever duration and hospitalization stay were shorter, while the proportion of incomplete $\mathrm{KD}$ was higher in the $2010-2014$ group $(26.4 \%$ vs. $46.2 \%, P<0.001)$. The rates of repeated IVIG treatment were not significantly different between the groups. The rate of total CALs was lower (23.6\% vs. $15.7 \%, P=0.014$ ) and severe CALs (aneurysm) tended to decrease in the $2010-2014$ (2.1\% vs. $0.6 \%)$ compared to the 2000-2004 group.

In laboratory indices, there were no significant differences in WBC count and differential, total protein, AST, or ALT values. However, there were significant differences in level of hemoglobin ( $10.8 \mathrm{~g} / \mathrm{dL}$ vs. $11.5 \mathrm{~g} / \mathrm{dL}, P<0.001)$, platelet count at presentation $\left(318,000 / \mathrm{mm}^{3}\right.$ vs. $336,000 / \mathrm{mm}^{3}$, $P=0.012)$ and follow-up $\left(513,000\right.$ vs. $431,000 / \mathrm{mm}^{3}$, $P<0.001)$, CRP $(10.4 \mathrm{mg} / \mathrm{dL}$ vs. $8.8 \mathrm{mg} / \mathrm{dL}, P=0.002)$, ESR $(57 \mathrm{~mm} / \mathrm{h}$ vs. $74 / \mathrm{mm} / \mathrm{h}, P<0.001)$, and albumin $(3.5 \mathrm{~g} / \mathrm{dL}$ vs. $3.8 \mathrm{~g} / \mathrm{dL}, P<0.001$ ) (Table 2). The ESR estimation method was changed from the Wintrobe method to the automated analyzer method during the study period in both hospitals, which may have affected the values in this study.
Table 1 Clinical and laboratory findings in complete KD and incomplete KD

\begin{tabular}{|c|c|c|c|}
\hline & $\begin{array}{l}\text { Complete KD } \\
(n=387)\end{array}$ & $\begin{array}{l}\text { Incomplete KD } \\
(n=228)\end{array}$ & $P$ \\
\hline Age (month) & $30.9 \pm 20.3$ & $27.7 \pm 22.9$ & 0.069 \\
\hline Sex (male/female) & $233 / 154$ & $142 / 86$ & 0.669 \\
\hline \multicolumn{4}{|l|}{ Fever (day) } \\
\hline Preadmission & $4.5 \pm 1.7$ & $4.6 \pm 2.1$ & 0.795 \\
\hline Total & $6.8 \pm 2.6$ & $6.6 \pm 2.7$ & 0.515 \\
\hline Hospitalization (day) & $7.6 \pm 3.6$ & $6.6 \pm 3.2$ & $<0.001$ \\
\hline Repeated IVIG, n (\%) & $46(11.9)$ & $13(5.7)$ & 0.015 \\
\hline CALs, n (\%) & $73(18.9)$ & $46(20.2)$ & 0.751 \\
\hline Ectasia & $69(17.8)$ & $42(18.4)$ & 0.914 \\
\hline Aneurysm & $4(1.0)$ & $4(1.8)$ & 0.477 \\
\hline WBC $\left(/ \mathrm{mm}^{3}\right)$ & $15,000 \pm 5100$ & $15,000 \pm 5000$ & 0.991 \\
\hline Neutrophil (\%) & $66.1 \pm 15.4$ & $61.3 \pm 15.6$ & $<0.001$ \\
\hline Lymphocyte (\%) & $22.5 \pm 12.4$ & $26.8 \pm 12.4$ & $<0.001$ \\
\hline Hemoglobin (g/dL) & $11.1 \pm 1.1$ & $11.2 \pm 1.0$ & 0.665 \\
\hline Platelet $\left(x-10^{3} / \mathrm{mm}^{3}\right)$ & $323 \pm 124$ & $335 \pm 140$ & 0.086 \\
\hline Platelet, follow-up & $473 \pm 189$ & $456 \pm 174$ & 0.098 \\
\hline CRP (mg/dL) & $10.0 \pm 6.3$ & $8.8 \pm 5.7$ & 0.016 \\
\hline $\operatorname{ESR}(\mathrm{mm} / \mathrm{h})$ & $66 \pm 31$ & $67 \pm 27$ & 0.593 \\
\hline Total protein (g/dL) & $6.5 \pm 0.7$ & $6.5 \pm 0.6$ & 0.995 \\
\hline Albumin (g/dL) & $3.6 \pm 0.4$ & $3.7 \pm 0.5$ & 0.004 \\
\hline AST (IU/L) & $96 \pm 161$ & $79 \pm 241$ & 0.304 \\
\hline ALT (IU/L) & $127 \pm 155$ & $95 \pm 171$ & 0.018 \\
\hline ALT <40 IU, n (\%) & $164(42.4)$ & $123(53.9)$ & 0.006 \\
\hline ALT 41-99 IU, n (\%) & $81(20.9)$ & $50(21.9)$ & 0.761 \\
\hline ALT > $100 \mathrm{IU}, \mathrm{n}(\%)$ & $142(36.7)$ & $55(24.1)$ & 0.001 \\
\hline
\end{tabular}

Values are mean \pm SD or $n(\%)$

KD Kawasaki disease, IVIG intravenous immunoglobulin, CALs coronary artery lesions, WBC white blood cell, CRP C-reactive protein, ESR erythrocyte sedimentation rate, AST aspartate aminotransferase, $A L T$ alanine aminotransferase

Because some laboratory values can be affected by age, stage of disease including fever duration, and other factors, we analyzed the KD subgroup with a fever duration of 5 days or 6 days $(n=204)$, and the data are expressed in Table 3. Also, recent KD patients had shorter hospital stays, a higher proportion of incomplete $\mathrm{KD}$, lower incidence of CALs, higher values of hemoglobin, albumin, and ESR, and lower CRP and follow-up platelet values compared to the patients with the same fever duration and age in the past KD patients (Table 3). Also, we analyzed the subgroup with complete $\mathrm{KD}(n=387)$ and that with incomplete $\mathrm{KD}(n=228)$, independently. The results of laboratory and clinical indices were nearly identical to those in the total KD group, although a few clinical parameters, such as CALs in the complete KD group, did not reach statistical significance (Tables 4 and 5). In the incomplete KD subgroup, there were no differences in the 
Table 2 Clinical and laboratory findings in the 2000-2004 group and the 2010-2014 group $(n=615)$

\begin{tabular}{|c|c|c|c|}
\hline & $\begin{array}{l}2000-2004 \\
(n=284)\end{array}$ & $\begin{array}{l}2010-2014 \\
(n=331)\end{array}$ & $P$ \\
\hline Age (month) & $30.5 \pm 22.3$ & $29.1 \pm 20.5$ & 0.433 \\
\hline $\operatorname{Sex}(M / F)$ & $168 / 116$ & $207 / 124$ & 0.408 \\
\hline \multicolumn{4}{|l|}{ Fever (day) } \\
\hline Preadmission & $4.9 \pm 2.1$ & $4.2 \pm 1.5$ & $<0.001$ \\
\hline Total & $7.2 \pm 3.2$ & $6.4 \pm 2.0$ & $<0.001$ \\
\hline Hospitalization (d) & $8.5 \pm 4.1$ & $6.1 \pm 2.4$ & $<0.001$ \\
\hline Incomplete KD, n (\%) & $75(26.4)$ & $153(46.2)$ & $<0.001$ \\
\hline Repeated IVIG, n (\%) & $26(9.2)$ & $33(10)$ & 0.784 \\
\hline CALs, n (\%) & $67(23.6)$ & $52(15.7)$ & 0.014 \\
\hline Ectasia & $61(21.5)$ & $50(15.1)$ & 0.046 \\
\hline Aneurysm & $6(2.1)$ & $2(0.6)$ & 0.153 \\
\hline WBC $\left(/ \mathrm{mm}^{3}\right)$ & $15,200 \pm 5100$ & $14,900 \pm 5200$ & 0.476 \\
\hline Neutrophil (\%) & $63.4 \pm 16.5$ & $65 \pm 14.8$ & 0.226 \\
\hline Lymphocyte (\%) & $23.4 \pm 13$ & $24.7 \pm 12.2$ & 0.197 \\
\hline Hemoglobin (g/dL) & $10.8 \pm 0.9$ & $11.5 \pm 0.9$ & $<0.001$ \\
\hline Platelet $\left(/ \mathrm{mm}^{3}\right)$ & $318 \pm 159$ & $336 \pm 98$ & 0.012 \\
\hline Platelet, follow-up & $513 \pm 207$ & $431 \pm 155$ & $<0.001$ \\
\hline CRP (mg/dL) & $10.4 \pm 6.8$ & $8.8 \pm 5.3$ & 0.002 \\
\hline $\mathrm{ESR}(\mathrm{mm} / \mathrm{h})$ & $57 \pm 23$ & $74 \pm 32$ & $<0.001$ \\
\hline Total protein (g/dL) & $6.5 \pm 0.7$ & $6.5 \pm 0.6$ & 0.368 \\
\hline Albumin (g/dL) & $3.5 \pm 0.4$ & $3.8 \pm 0.5$ & $<0.001$ \\
\hline AST (IU/L) & $77 \pm 145$ & $62 \pm 75$ & 0.128 \\
\hline ALT (IU/L) & $111 \pm 146$ & $118 \pm 174$ & 0.625 \\
\hline ALT <40 IU, n (\%) & $131(46.2)$ & $156(47.1)$ & 0.654 \\
\hline ALT 41-99 IU, n (\%) & $63(22.2)$ & $68(20.5)$ & 0.684 \\
\hline ALT > $100 \mathrm{IU}, \mathrm{n}(\%)$ & 90 (31.6) & $107(32.3)$ & 0.863 \\
\hline
\end{tabular}

Values are mean \pm SD or $n$ (\%). Abbreviations as in Table 1

prevalence rates of each clinical diagnostic signs in both periods (data not shown).

\section{Discussion}

Since the first report of KD in the early 1960s in Japan, the disease has now appeared in over 60 countries around the world [10, 20]. Japan and Korea currently have the highest incidences of KD in the world; 264.8/ 100,000 in children aged $<5$ years in 2012 in Japan [21], and $194.7 / 10^{5}$ in 2014 in Korea [22]. KD has currently become one of the common diseases in Korea.

In the present study, we found that KD patients in Korea are increasing, but clinical and laboratory features might be changing to milder phenotypes over time. $\mathrm{Na}$ tionwide epidemiological studies have indicated that the proportion of patients with incomplete KD was as high as $20 \%$ in $2007-2008$ in Japan [23], and $42.2 \%$ of patients in 2009-2011 in Korea with no fatalities [15]. In
Table $3 \mathrm{KD}$ patients with fever duration of 5 or 6 days in the both groups $(n=204)$

\begin{tabular}{|c|c|c|c|}
\hline & $\begin{array}{l}2000-2004 \\
(n=100)\end{array}$ & $\begin{array}{l}2010-2014 \\
(n=104)\end{array}$ & $P$ \\
\hline Age (month) & $31.1 \pm 22$ & $31 \pm 20.1$ & 0.978 \\
\hline $\operatorname{Sex}(M / F)$ & $56 / 44$ & $64 / 40$ & 0.477 \\
\hline \multicolumn{4}{|l|}{ Fever duration (day) } \\
\hline Preadmission & $5.4 \pm 0.5$ & $5.3 \pm 0.4$ & 0.047 \\
\hline Total & $7.1 \pm 1.8$ & $6.8 \pm 1.5$ & 0.104 \\
\hline Hospitalization (day) & $8.6 \pm 2.8$ & $5.8 \pm 1.8$ & $<0.001$ \\
\hline Incomplete KD, n (\%) & $22(22)$ & $46(44.2)$ & 0.001 \\
\hline Repeated IVIG, n (\%) & $7(7)$ & $10(9.6)$ & 0.615 \\
\hline CALs, n (\%) & $31(31)$ & $17(16.3)$ & 0.020 \\
\hline Eectasia & $29(29)$ & $17(16.3)$ & 0.044 \\
\hline Aneurysm & $2(2)$ & $0(0)$ & 0.239 \\
\hline WBC $\left(/ \mathrm{mm}^{3}\right)$ & $15,500 \pm 4800$ & $14,800 \pm 5100$ & 0.318 \\
\hline Neutrophil (\%) & $65.7 \pm 13.7$ & $66.8 \pm 15.0$ & 0.572 \\
\hline Lymphocyte (\%) & $21.8 \pm 11.7$ & $23.2 \pm 12.6$ & 0.407 \\
\hline Hemoglobin (g/dL) & $10.7 \pm 0.8$ & $11.4 \pm 0.9$ & $<0.001$ \\
\hline Platelet $\left(x-10^{3} / \mathrm{mm}^{3}\right)$ & $323 \pm 125$ & $317 \pm 78$ & 0.038 \\
\hline Platelet, follow-up & $532 \pm 168$ & $407 \pm 120$ & $<0.001$ \\
\hline CRP (mg/dL) & $12.5 \pm 7.1$ & $9.3 \pm 6.1$ & 0.001 \\
\hline $\mathrm{ESR}(\mathrm{mm} / \mathrm{h})$ & $58 \pm 24$ & $77 \pm 39$ & $<0.001$ \\
\hline Total protein (g/dL) & $6.4 \pm 0.6$ & $6.4 \pm 0.6$ & 0.848 \\
\hline Albumin (g/dL) & $3.5 \pm 0.4$ & $3.7 \pm 0.4$ & 0.002 \\
\hline AST (IU/L) & $59 \pm 90$ & $71 \pm 110$ & 0.397 \\
\hline ALT (IU/L) & $102 \pm 125$ & $114 \pm 177$ & 0.570 \\
\hline ALT <40 IU, n (\%) & $46(46)$ & $43(41.3)$ & 0.573 \\
\hline ALT 41-99 IU, n (\%) & $23(23)$ & $33(31.7)$ & 0.209 \\
\hline ALT > $100 \mathrm{IU}, \mathrm{n}(\%)$ & $31(31)$ & $28(26.9)$ & 0.540 \\
\hline
\end{tabular}

Values are mean $\pm \mathrm{SD}$ or $\mathrm{n}(\%)$. Abbreviations as in Table 1

this study, we confirmed this trend as well as in our previous studies [16, 17], the proportion of incomplete $\mathrm{KD}$ significantly increased from $26.4 \%$ in 2000-2004 to $46.2 \%$ in $2010-2014$. In the present study, we found that incomplete $\mathrm{KD}$ patients had fewer cases of repeated IVIG treatment $(5.7 \%$ vs. $11.9 \%, P=0.015)$ and less severe values of some laboratory indices such as WBC differentials, CRP, albumin and ALT, but the rate of CALs in the incomplete KD patients was not different from that in complete KD patients $(20.2 \%$ vs. $18.9 \%, P=0.75)$ (Table 1). Other studies have also indicated that incomplete KD and complete KD patients had similar laboratory findings with similar incidences of CALs [24, 25]. These findings suggest that KD may appear as various phenotypes and immune responses against KD pathogen(s) and/or insults from the infection are similar in both KD patient groups, with individual variations such as involvement of ALT/ALT elevation and CALs. Thus, 
Table 4 Clinical and laboratory findings in complete KD in the 2000-2004 group and the 2010-2014 group $(n=387)$

\begin{tabular}{|c|c|c|c|}
\hline & $\begin{array}{l}2000-2004 \\
(n=210)\end{array}$ & $\begin{array}{l}2010-2014 \\
(n=177)\end{array}$ & $P$ \\
\hline Age (month) & $30.9 \pm 21.5$ & $31 \pm 18.9$ & 0.938 \\
\hline $\operatorname{Sex}(M / F)$ & $124 / 86$ & 109/68 & 0.677 \\
\hline \multicolumn{4}{|l|}{ Fever (day) } \\
\hline Preadmission & $4.8 \pm 1.8$ & $4.3 \pm 1.6$ & 0.009 \\
\hline Total & $6.9 \pm 2.9$ & $6.5 \pm 2.3$ & 0.392 \\
\hline Hospitalization (d) & $8.5 \pm 4.1$ & $6.5 \pm 2.8$ & $<0.001$ \\
\hline Repeated IVIG, n (\%) & $24(11.4)$ & $22(12.4)$ & 0.754 \\
\hline CALs, n (\%) & $45(21.4)$ & $28(15.8)$ & 0.192 \\
\hline Ectasia & $42(20)$ & $27(15.3)$ & 0.234 \\
\hline Aneurysm & $3(1.4)$ & $1(0.6)$ & 0.629 \\
\hline WBC $\left(/ \mathrm{mm}^{3}\right)$ & $15,100 \pm 5100$ & $15,000 \pm 5200$ & 0.880 \\
\hline Neutrophil (\%) & $64.5 \pm 16.2$ & $67.9 \pm 14.2$ & 0.031 \\
\hline Lymphocyte (\%) & $22.8 \pm 12.8$ & $22.1 \pm 12.1$ & 0.561 \\
\hline Hemoglobin (g/dL) & $10.8 \pm 1.2$ & $11.5 \pm 0.8$ & $<0.001$ \\
\hline Platelet $\left(/ \mathrm{mm}^{3}\right)$ & $315 \pm 147$ & $332 \pm 89$ & 0.122 \\
\hline Platelet, follow-up & $501 \pm 208$ & $443 \pm 161$ & $<0.001$ \\
\hline CRP (mg/dL) & $10.4 \pm 6.8$ & $9.5 \pm 5.6$ & 0.192 \\
\hline ESR (mm/h) & $56 \pm 24$ & $74 \pm 32$ & $<0.001$ \\
\hline Total protein (g/dL) & $6.5 \pm 0.7$ & $6.5 \pm 0.6$ & 0.656 \\
\hline Albumin (g/dL) & $3.5 \pm 0.4$ & $3.8 \pm 0.5$ & $<0.001$ \\
\hline AST (IU/L) & $89 \pm 166$ & $104 \pm 156$ & 0.338 \\
\hline ALT (IU/L) & $127 \pm 161$ & $126 \pm 149$ & 0.928 \\
\hline ALT <40 IU, n (\%) & $89(42.4)$ & $75(42.4)$ & 0.918 \\
\hline ALT 40-100 IU, n (\%) & $45(21.4)$ & $36(20.3)$ & 0.900 \\
\hline ALT > $100 \mathrm{IU}, \mathrm{n}(\%)$ & $76(36.2)$ & $66(37.3)$ & 0.750 \\
\hline
\end{tabular}

Values are mean \pm SD or $\mathrm{n}(\%)$. Abbreviations as in Table 1

our results suggest that patients with incomplete KD may have milder clinical manifestations with less systemic inflammation reflected by some laboratory parameters compared to patients with complete KD. As for incomplete KD patients, Pediatricians in Korea have skillfully used other signs such as skin changes at the Bacille Calmette-Guérin inoculation site for infants or slit lamp examination to search the anterior uveitis for older children [26, 27], as well as laboratory findings.

The reduced risk of CALs in recent patients in this study could be attributable to early diagnosis and early IVIG in incomplete KD treatment as suggested in other studies $[14,15,23]$. Our KD patents in the 2010-2014 group also visited the hospital earlier (4.9 days vs. 4.2 days, $P<0.001)$ and subsequently they were treated with IVIG earlier than the patients in the past KD group. On the other hand, the complete and incomplete KD groups had the same preadmission fever duration (4.5 days vs. 4.6 days, $P=0.80$ ), and incomplete $\mathrm{KD}$ patients received
Table 5 Clinical and laboratory findings in incomplete KD in the 2000-2004 group and the 2010-2014 group $(n=228)$

\begin{tabular}{|c|c|c|c|}
\hline & $\begin{array}{l}2000-2004 \\
(n=74)\end{array}$ & $\begin{array}{l}2010-2014 \\
(n=154)\end{array}$ & $P$ \\
\hline Age (month) & $29.3 \pm 24.8$ & $26.9 \pm 22.0$ & 0.456 \\
\hline $\operatorname{Sex}(M / F)$ & $44 / 30$ & $98 / 56$ & 0.562 \\
\hline \multicolumn{4}{|l|}{ Fever (day) } \\
\hline Preadmission & $5.5 \pm 2.8$ & $4.2 \pm 1.5$ & $<0.001$ \\
\hline Total & $7.9 \pm 3.9$ & $6.0 \pm 1.6$ & $<0.001$ \\
\hline Hospitalization (d) & $8.6 \pm 4.5$ & $5.6 \pm 1.7$ & $<0.001$ \\
\hline Repeated IVIG, n (\%) & $6(8.1)$ & $7(4.5)$ & 0.358 \\
\hline CALs, n (\%) & $22(29.7)$ & $24(15.6)$ & 0.015 \\
\hline Ectasia & $19(25.7)$ & $23(14.9)$ & 0.067 \\
\hline Aneurysm & $3(4.0)$ & $1(0.6)$ & 0.102 \\
\hline $\mathrm{WBC}\left(/ \mathrm{mm}^{3}\right)$ & $15,500 \pm 5000$ & $14,800 \pm 4900$ & 0.291 \\
\hline Neutrophil (\%) & $60.5 \pm 17.1$ & $61.6 \pm 14.8$ & 0.599 \\
\hline Lymphocyte (\%) & $24.9 \pm 13.7$ & $27.7 \pm 11.7$ & 0.116 \\
\hline Hemoglobin (g/dL) & $10.7 \pm 0.8$ & $11.4 \pm 1.0$ & $<0.001$ \\
\hline Platelet $\left(/ \mathrm{mm}^{3}\right)$ & $324 \pm 191$ & $341 \pm 108$ & 0.010 \\
\hline Platelet, follow-up & $550 \pm 291$ & $418 \pm 146$ & $<0.001$ \\
\hline CRP (mg/dL) & $10.4 \pm 6.8$ & $8.0 \pm 4.9$ & 0.008 \\
\hline ESR (mm/h) & $60 \pm 23$ & $70 \pm 28$ & $<0.001$ \\
\hline Total protein (g/dL) & $6.4 \pm 0.7$ & $6.5 \pm 0.6$ & 0.703 \\
\hline Albumin (g/dL) & $3.5 \pm 0.4$ & $3.9 \pm 0.5$ & $<0.001$ \\
\hline AST (IU/L) & $43 \pm 39$ & $96 \pm 297$ & 0.030 \\
\hline ALT (IU/L) & $65 \pm 82$ & $108 \pm 174$ & 0.021 \\
\hline ALT <40 IU, n (\%) & $42(56.8)$ & $81(52.6)$ & 0.888 \\
\hline ALT 40-100 IU, n (\%) & $18(24.3)$ & $32(20.8)$ & 0.616 \\
\hline ALT > $100 \mathrm{IU}, \mathrm{n}(\%)$ & $14(18.9)$ & $41(26.6)$ & 0.241 \\
\hline
\end{tabular}

Values are mean \pm SD or $n(\%)$. Abbreviations as in Table 1

IVIG treatment later than complete KD patients (1.4 days vs. 1.1 days, $P<0.001)$, but there were no differences in CALs in the two groups. Therefore, other factors may also be associated with the low rate of CALs in recent years.

During a self-limited systemic inflammatory process in $\mathrm{KD}$, there is a peak (mean 6th day after fever onset) in systemic inflammation, reflected in the laboratory parameters $[9,19]$. We found that not only CALs but also some laboratory parameter values were less severe in the 2010-2014 KD patients than the 2000-2004 KD patients. In this series, CRP, albumin, hemoglobin, and platelet levels were significantly different in the two groups. Both groups of KD patients with the same fever duration (5 days or 6 days) and same mean age at presentation had identical results (Table 3). These findings were also observed when we analyzed patients with complete KD and those with incomplete KD separately in each time-period (Tables 4 and 5). 
These laboratory indices are contained in the AHA diagnostic criteria for incomplete KD [1]. Albumin, hemoglobin, and CRP are very sensitive parameters that reflect systemic inflammation in acute $\mathrm{KD}$, and they can vary significantly in daily examinations. Therefore, confirmation with the elevation of CRP, the reduction of albumin and hemoglobin, and the appearance of elevated transaminase and/or pyuria in daily examination may be helpful for early diagnosis in early-presented incomplete KD patients.

Platelet count may begin to increase after the peak of inflammation in the acute stage, suggesting that it has a role in the recovery reaction to $\operatorname{KD}[9,19]$. This was satisfied by all KD patients in this study, with each patient confirming platelet elevation during admission. In addition, we found that the platelet count and immunoglobulin G (IgG), IgM and IgA levels increased in the early convalescent stage of $\mathrm{KD}$, and the extent of increase in these parameters correlated with each other [unpublished observation]. These findings suggest that platelets and immunoglobulins may be involved in the recovery from $\mathrm{KD}$ and the extent of increased the parameters in the subacute stage may reflect the extent of systemic inflammation. This characteristic of KD inflammation could be helpful for KD patient selection after IVIG therapy.

It has been reported that higher CRP, higher maximum platelet, lower albumin, or lower hemoglobin values are associated with IVIG-non responsiveness and the risk of CALs [28-31]. Our laboratory results provided evidence of changing epidemiology in KD in Korea, and this may be the first laboratory-proven study to demonstrate the results.

It has been reported that initially severe phenotypes of the diseases become milder over time in many infectious diseases, including scarlet fever, endocarditis, and pandemic influenza [11, 32, 33]. Also, these changes have been observed in infection-related immune-mediated diseases, such as acute rheumatic fever and APSGN [11-13]. Recent APSGN patients in Korea had a milder phenotype than patients in the past, although the incidence of the disease is markedly decreasing as well as in other developed countries [13]. Although the reason for changes in clinical features in $\mathrm{KD}$ is unknown, it could be attributable in part that KD pathogenic strain(s) or unknown herd immunity against the pathogens may have changed over time.

Because of early visit to hospital and changed phenotype of KD in Korea, application of the laboratory diagnostic criteria suggested by the AHA for incomplete KD patients with short fever duration can have some clinical obstacles, such as waiting for 1-2 days or more after admission [34]. Moreover, early IVIG treatment may affect the appearance of clinical diagnostic criteria of patients with potentially complete KD. These observations could explain, in part, why the number of patients with incomplete KD has increased in Korea.
This retrospective study may have some limitations. We analyzed diagnostic clinical signs through the initial description in medical records and applied diagnostic criteria regardless of the presence of CALs. Thus, additional signs that appeared during hospitalization could be omitted, and the number of incomplete KD patients could have been over-estimated. Although the number of subjects in this study was not small, this data may not be representative of the current situation in Korea. Finally, there might be some differences in patient care policies such as hospitalization and follow-up echocardiography, according to the time periods and different hospitals.

\section{Conclusions}

Recently-admitted KD patients were more likely to present with incomplete KD and have a lower incidence of CALs, lower levels of CRP and platelet count, and higher levels of albumin and hemoglobin compared to similar patients a decade ago. These findings suggest that clinical features of KD became milder over time. Therefore, new diagnostic criteria for early IVIG treatment, including the laboratory criteria for patients that present early and confirmation after IVIG treatment for patient selection, may be needed in Korea in the near future.

\section{Abbreviations \\ ALT: Alanine aminotransferase; AST: Aspartate aminotransferase; CAL: Coronary artery lesion; CRP: C-reactive protein; ESR: Erythrocyte sedimentation rate; IVIG: Intravenous immunoglobulin; KD: Kawasaki disease; WBC: White blood cell}

\section{Acknowledgements}

This study has no fund. We thank Drs. You-Sook Youn, Myung-Suk Shin, Ji-Yoon Han, and other colleagues for patient care and data collection during the study period.

Funding

This study has no fund.

\section{Availability of data and materials}

The datasets used and/or analysed during the current study are available from the corresponding author on reasonable request.

\section{Authors' contributions}

$K Y L$ designed the study, performed the statistical analysis and drafted the manuscript; HRK participated in preliminary data collection and wrote the initial manuscript; JWY, SJ, and JUR participated in the study design, patient care, data collection, and revision of the manuscript for critical content. All authors read and approved the final manuscript.

\section{Ethics approval and consent to participate}

At the time of admission, the written informed consents were obtained from the parents/caregivers of all children for the medical records to be used in this study. The study was approved by the Institutional Review Board of Chungnam National University Hospital (2016-11-022), and Institutional Review Board of The Catholic University of Korea Daejeon St. Mary's Hospital (DC16RIMI10062).

Consent for publication

Not applicable.

Competing interests

The authors declare that they have no competing interests. 


\section{Author details}

'Department of Pediatrics, Chungnam National University Hospital, School of Medicine, Chungnam National University, Daejeon, Korea. ${ }^{2}$ Departments of Pediatrics, Daejeon St. Mary's Hospital, College of Medicine, The Catholic University of Korea, 64 Daeheung-ro, Jung-gu, Daejeon 34943, Republic of Korea.

Received: 24 April 2017 Accepted: 1 August 2017

Published online: 07 August 2017

\section{References}

1. Newburger JW, Takahashi M, Gerber MA, Gewitz MH, Tani LY, Burns JC, et al. Diagnosis, treatment, and long-term management of Kawasaki disease: a statement for health professionals from the committee on rheumatic fever, Endocarditis, and Kawasaki disease, council on cardiovascular disease in the Young, American Heart Association. Pediatrics. 2004;114:1708-33.

2. Kushner HI, Abramowsky CR. An old autopsy report sheds light on a "new" disease: infantile polyarteritis nodosa and Kawasaki disease. Pediatr Cardiol. 2010;31:490-6

3. Kawasaki T. Acute febrile muco-cutaneous lymph node syndrome in young children with unique digital desquamation. Arerugi. 1967;16:178-222.

4. Park JS, Suh CJ, Cho SH, Lee DB. Mucocutaneous lymph node syndrome: five case report. J Korean Pediatr Soc. 1973;16:61-7.

5. Lue HC, Philip S, Chen MR, Wang JK, Wu MH. Surveillance of Kawasaki disease in Taiwan and review of the literature. Acta Paediatr Taiwan. 2004;45:8-14.

6. Zhang $T$, Yanagawa $H$, Nakamura $Y$. The profiles of Kawasaki disease in China. J Epidemiol. 2001;11:103-8.

7. Singh S, Aulakh R, Bhalla AK, Suri D, Manojkumar R, Narula N, et al. Is Kawasaki disease incidence rising in Chandigarh, North India? Arch Dis Child. 2011;96:137-40.

8. Lee KY, Han JW, Lee JS. Kawasaki disease may be a hyperimmune reaction of genetically-susceptible children to variants of normal environmental flora. Med Hypotheses. 2007;69:642-51.

9. Lee KY, Rhim JW, Kang JH. Kawasaki disease: laboratory findings and an immunopathogenesis on the premise of a "protein homeostasis system". Yonsei Med J. 2012;53:262-75.

10. Singh S, Vignesh P, Burgner D. The epidemiology of Kawasaki disease: a global update. Arch Dis Child. 2015;100:1084-8.

11. Quinn RW. Comprehensive review of morbidity and mortality trends for rheumatic fever, streptococcal disease, and scarlet fever: the decline of rheumatic fever. Clin Infect Dis. 1989;11:928-53.

12. Lee GM, Wessels MR. Changing epidemiology of acute rheumatic fever in the United States. Clin Infect Dis. 2006:42:448-50.

13. Keum SW, Hur SM, Youn YS, Rhim JW, Suh JS, Lee KY, et al. Changes in acute poststreptococcal glomerulonephritis: an observation study at a single Korean hospital over two decades. Child Kidney Dis. 2015;19:112-7.

14. Nakamura Y, Yashiro M, Uehara R, Sadakane A, Tsuboi S, Aoyama Y, et al. Epidemiologic features of Kawasaki disease in Japan: results of the 2009-2010 nationwide survey. J Epidemiol. 2012;22:216-21.

15. Kim GB, Han JW, Park YW, Song MS, Hong YM, Cha SH, et al. Epidemiologic features of Kawasaki disease in South Korea: data from nationwide survey, 2009-2011. Pediatr Infect Dis J. 2014;33:24-7.

16. Kang HJ, Kim GN, Kil HR. Changes of clinical characteristics and outcomes in patients with Kawasaki disease over the past 7 years in a single center study. Korean J Pediatr. 2013;56:389-95.

17. Rhim JW, Youn YS, Han JW, Lee SJ, Oh JH, Lee KY. Changes in Kawasaki disease during 2 decades at a single institution in Daejeon. Korea Pediatr Infect Dis J. 2014:33:372-5.

18. Research Committee on Kawasaki disease. Report of subcommittee on standardization of diagnostic criteria and reporting of coronary artery lesions in Kawasaki disease. Tokyo: Ministry of Health and Welfare; 1984.

19. Lee KY, Han JW, Hong JH, Lee HS, Lee JS, Whang KT. Inflammatory processes in Kawasaki disease reach their peak at the sixth day of fever onset: laboratory profiles according to duration of fever. J Korean Med Sci. 2004;19:501-4.

20. Uehara R, Belay ED. Epidemiology of Kawasaki disease in Asia, Europe, and the United States. J Epidemiol. 2012:22:79-85.

21. Makino N, Nakamura Y, Yashiro M, Ae R, Tsuboi S, Aoyama Y, et al. Descriptive epidemiology of Kawasaki disease in Japan, 2011-2012: from the results of the 22nd nationwide survey. J Epidemiol. 2015;25:239-45.
22. Kim GB, Park S, Eun LY, Han JW, Lee SY, Yoon KL, et al. Epidemiology and clinical features of Kawasaki disease in South Korea, 2012-2014. Pediatr Infect Dis J. 2017;36:482-5.

23. Sudo D, Monobe $Y$, Yashiro M, Mieno MN, Uehara R, Tsuchiya K, et al. Coronary artery lesions of incomplete Kawasaki disease: a nationwide survey in Japan. Eur J Pediatr. 2012;171:651-6.

24. Yellen ES, Gauvreau K, Takahashi M, Burns JC, Shulman S, Baker AL, et al. Performance of 2004 American Heart Association recommendations for treatment of Kawasaki disease. Pediatrics. 2010;125:e234-41.

25. Manlhiot C, Christie E, McCrindle BW, Rosenberg H, Chahal N, Yeung RS. Complete and incomplete Kawasaki disease: two sides of the same coin. Eur J Pediatr. 2012;171:657-62.

26. Seo JH, Yu JJ, Ko HK, Choi HS, Kim YH, Ko JK. Diagnosis of incomplete Kawasaki disease in infants based on an inflammation at the Bacille Calmette-Guérin inoculation site. Korean Circ J. 2012:42:823-9.

27. Choi HS, Lee SB, Kwon JH, Kim HS, Sohn S, Hong YM. Uveitis as an important ocular sign to help early diagnosis in Kawasaki disease. Korean J Pediatr. 2015;58:374-9.

28. Kobayashi T, Inoue Y, Takeuchi K, Okada Y, Tamura K, Tomomasa T, et al. Prediction of intravenous immunoglobulin unresponsiveness in patients with Kawasaki disease. Circulation. 2006;113:2606-12.

29. Wei M, Huang M, Chen S, Huang G, Huang M, Qiu D, et al. A multicenter study of intravenous immunoglobulin non-response in Kawasaki disease. Pediatr Cardiol. 2015:36:1166-72.

30. Kim JJ, Hong YM, Yun SW, Han MK, Lee KY, Song MS, et al. Korean Kawasaki disease genetics consortium. Assessment of risk factors for Korean children with Kawasaki disease. Pediatr Cardiol. 2012;33:513-20.

31. Tremoulet AH, Best BM, Song S, Wang S, Corinaldesi E, Eichenfield JR, et al. Resistance to intravenous immunoglobulin in children with Kawasaki disease. J Pediatr. 2008;153:117-21.

32. Wang A. The changing epidemiology of infective endocarditis. J Am Coll Cardiol. 2012;59:1977-8.

33. Rhim JW, Go EJ, Lee KY, Youn YS, Kim MS, Park SH, et al. Pandemic 2009 H1N1 virus infection in children and adults: a cohort study at a single hospital throughout the epidemic. Int Arch Med. 2012;5:13.

34. Jun HO, Yu JJ, Kang SY, Seo CD, Baek JS, Kim YH, et al. Diagnostic characteristics of supplemental laboratory criteria for incomplete Kawasaki disease in children with complete Kawasaki disease. Korean J Pediatr. 2015;58:369-73.

\section{Submit your next manuscript to BioMed Central and we will help you at every step:}

- We accept pre-submission inquiries

- Our selector tool helps you to find the most relevant journal

- We provide round the clock customer support

- Convenient online submission

- Thorough peer review

- Inclusion in PubMed and all major indexing services

- Maximum visibility for your research

Submit your manuscript at www.biomedcentral.com/submit
) Biomed Central 